Copyright (C) 2014 by Academic Publishing House Researcher

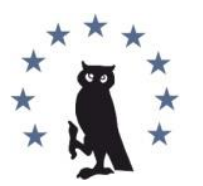

Published in the Russian Federation

European Researcher

Has been issued since 2010.

ISSN 2219-8229

E-ISSN 2224-0136

Vol. 82, No. 9-1, pp. 1628-1644, 2014

DOI: 10.13187/er.2014.82.1628

www.erjournal.ru

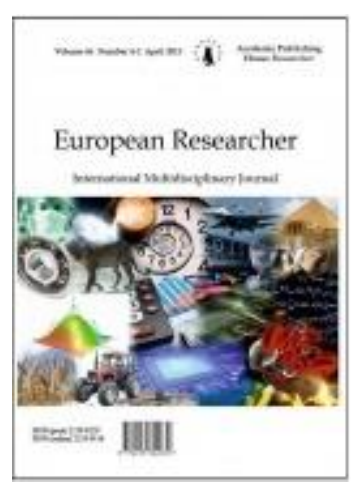

Economic Sciences

Экономические науки

UDC 330

\title{
Economic-Mathematical Modeling of the Impact of the Prime Cost of Products on the Effectiveness of the Activity of Entrepreneurial Establishments
}

\author{
${ }^{1}$ Mihail N. Dudin \\ ${ }^{2}$ Nikolaj V. Lyasnikov \\ 3 Aleksandr S. Senin
}

\author{
1-3 Russian Presidential Academy of National Economy and Public Administration, Russian Federation \\ 119571, Moskva city, Prospekt Vernadskogo, 82 \\ ${ }^{1}$ Doctor of Economic Sciences, Assistant Professor \\ E-mail: dudinmn@mail.ru \\ ${ }^{2}$ Doctor of Economic Sciences, Professor \\ ${ }^{3}$ Doctor of Economic Sciences, Professor
}

\section{Abstract}

Subject/topic. One of the key elements in managing the operating activity of organizations is managing expenditure, since expenditure, which is payments that need to be effected to be able to engage and retain economic resources, is one of the major factors that determine the organization's financial results, the cost-effectiveness of capital investments, and, ultimately, the cost of the business.

Aim/objectives. This work aims to investigate into the impact of the structure of the product's prime cost on the indicator of the product's cost-effectiveness.

Methodology. In putting this article together, the author employed such methods of analysis as legal, comparative, economic-statistical, and correlational.

Inferences/significance. The practical significance of this work lies in that the author finetunes the concept and composition of the prime cost of products and establishes equations for simple linear regression between the share of costs in the composition of the prime cost and the level of cost-effectiveness of the product across various types of economic activity in the Russian Federation (RF) in 2012. Knowing the share of costs in the structure of the product's self-cost across various types of economic activity in the RF in 2012, we shall be able to use the derived models to assess the average level of the product's cost-effectiveness.

Keywords: prime cost; costs; expenses; cost of sales; cost structure; product profitability.

\section{Введение}

Экономика современных развитых и развивающихся стран, а также стран, находящихся в процессе качественного перехода, обладает значительным эволюционным 
потенциалом, который требует грамотного и рационального его освоения (Lyasnikov et al, 2014). Не последнюю роль, как в формировании, так и в использовании эволюционного потенциала играет экономико-математическое моделированию развития процессов в предпринимательских структурах. Развитие мирового предпринимательства в промышленности, сельском хозяйстве, сфере торговли и услуг напрямую связано со становлением и формированием экономико-математического моделирования процессов развития и функционирования социально-экономических систем. (Dudin et al, 2014). Как свидетельствуют исторические источники, сформировавшись первоначально как торговое и ремесленное, в дальнейшем мировое предпринимательство, эффективно внедряя результаты научно-технического прогресса, быстро эволюционировало к мануфактурному и промышленному производству. В настоящее время мировое предпринимательство представляет собой сложную экономическую агломерацию, в которой сформированы основные сегменты (малый, средний и крупный бизнес) и взаимозависимые отрасли. Прошедшие пять технологических укладов показали, что экономическое развитие возможно только при условии постоянного продуцирования и внедрения новаций. Современный шестой технологический уклад можно рассматривать как уклад, характеризующий полный переход мировых общественно-экономических отношений от индустриализации к информатизации и экономико-математическому моделированию развития процессов в социально-экономических структурах, в том числе и предпринимательских структурах (Baranenko et al, 2014).

\section{Результаты исследования и их обсуждение}

В системе финансового менеджмента особое внимание уделяется так называемым постоянным расходам нефинансового характера (это, прежде всего амортизационные отчисления) и финансового характера (проценты к уплате за пользование долгосрочными заемными средствами); величины этих расходов используются для расчета количественных характеристик соответственно операционного и финансового рисков.(Kovalev and Kovalev Wit, 2011).

Цели эффективного управления расходами следующие:

- увеличение прибыли за счет снижения затрат без роста объема продаж или наряду с этим ростом;

- повышение финансовой устойчивости предприятия;

- повышение конкурентоспособности и, соответственно, снижение цен, увеличение доли рынка и тем самым увеличение объема продаж, так как производимая продукция (работ, услуги) должна быть привлекательной для потребителя.

Себестоимость продукции - экономическая категория, включающая все расходы предприятия, связанные с производством и реализацией определенного вида конкретной продукции, работ, услуг.

Согласно другому определению, себестоимость продукции (работ, услуг) - это затраты предприятия на их производство (производственная себестоимость) и реализацию (полная себестоимость).

Таким образом, появляется еще один термин - «затраты», т.е. отдельные элементы расходов предприятия по основным видам деятельности.

С.А. Сироткин под затратами понимает «денежные средства организации или стоимостное выражение средств (активов) организации, переданных другим юридическим или физическим лицам в счет погашения текущих и будущих обязательств (задолженности) в результате приобретения ресурсов, средств труда и прочих обязательных платежей. При этом такие обязательства могут возникать в связи с приобретением сырья, материалов, оплатой труда работников, социальными отчислениями. (Sirotkin, 2011)

Понятие «расходы», применяемое в «Международных стандартах финансовой отчётности» и в ПБУ 10/99 «Учет расходов», связано с формированием отчёта о прибылях и убытках, а затем и выявлением финансового результата. В бухгалтерском учёте расходами организации признаётся «уменьшение экономических выгод в результате выбытия активов и (или) возникновения обязательств, приводящее к уменьшению капитала этой 
организации, за исключением уменьшения вкладов по решению участников (собственников имущества)». Это определение приводится в ПБУ 10/99, в котором к тому же указывается: «Требования объективности и обоснованности формирования доходов и затрат обусловливает необходимость использования научно-методических подходов к реализации этого процесса».

Недостатком данного определения расходов является то, что оно не отвечает на вопрос, что это такое. ПБУ 10/99» определяет, что к расходам не относятся некоторые выбытия активов. Так, не признаются расходами:

- приобретение или создание вне оборотных активов;

- вклады в уставные (складочные) капиталы других организаций, приобретение акций $\mathrm{AO}$ и иных ценных бумаг не с целью перепродажи;

- платежи по договорам комиссии, агентским и иным аналогичным договорам;

- предварительная оплата и авансы в счет оплаты продукции, работ, услуг;

- погашение кредита, займов, полученных организацией.

В учебнике под редакцией А.А. Володина приводится следующее определение расходов предприятия: «Расходы предприятия - эта та часть его выплат в виде денежных средств и иного имущества, которая:

- выплачивается на безвозвратной основе;

- перестает быть собственностью предприятия;

- не связана с уменьшением имущества путем уменьшения вкладов по решению участников или собственников предприятия;

- включается в финансовую отчетность предприятия «Отчет о прибылях и убытках» и уменьшает налогооблагаемую прибыль (за исключением чрезвычайных расходов и в соответствии с требованиями налогового учета)».

Л.М. Бурмистрова под расходами предприятия понимает «уменьшение экономических выгод в результате выбытия денежных средств, иного имущества и (или) возникновения обязательств, приводящее к уменьшению капитала. (Burmistrova, 2009). частей:

Расходы предприятия по основным видам деятельности (РАСовд) состоят из двух

$$
P A C_{\text {овд }}=\text { ПЛД }+K 3 \text { (1) }
$$

где ПЛД - платежи предприятия (оплата расходов) в денежной и иной форме; КЗ кредиторская задолженность предприятия.

При формировании расходов по основным видам деятельности должна быть обеспечена их группировка по следующим элементам: материальные затраты; затраты на оплату труда; отчисления на социальные нужды; амортизация; прочие затраты. Затраты на производство - это совокупность расходов предприятия (рис. 1).

Из рис. 1 видно, что 


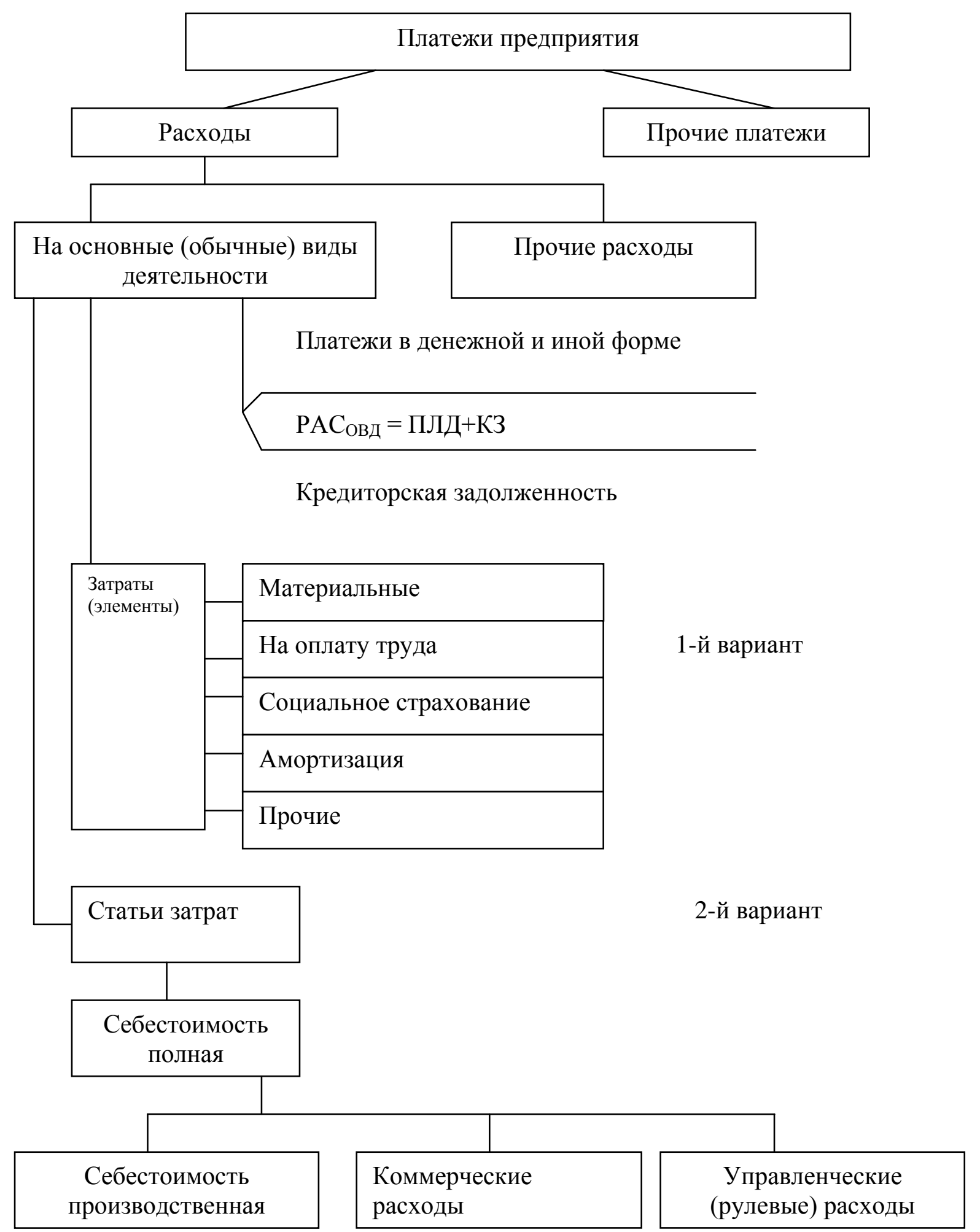

Рuc. 1. Расходы предприятия, взаимосвязь терминов.

Источник: составлено по данным (Volodin, 2011)

- расходы предприятия - это часть его платежей;

- расходы предприятия состоят из двух частей - расходы на основные виды деятельности и прочие расходы;

- расходы на основные виды деятельности включают две части - платежи в денежной и иной форме и кредиторскую задолженность; 
- расходы на основные виды деятельности образуют себестоимость продукции, работ, услуг;

- в себестоимость включаются затраты предприятия;

- затраты состоят из пяти обязательных элементов; кроме того, затрат могут состоять из ряда статей, определяемых предприятием самостоятельно;

- себестоимость бывает производственная (затрат на производство) и полная, включающая, кроме производственной себестоимости, коммерческие расходы (расходы на реализацию и сбыт) и управленческие расходы (расходы на содержание аппарата управления предприятия).

Разницу между затратами и расходами можно выразить следующим образом: затраты осуществляются в течение определённого периода. Завершение периода накопления затрат приводит к образованию либо активов, либо расходов. (Chernobriva and Gladkova, 2010)

Затраты могут быть расходами только в составе стоимости готовой реализованной продукции. Отсюда вполне оправданы замечания некоторых экономистов по поводу корректности названия бухгалтерских счетов 25 и 26.

Более точными были бы названия счета 25 «Общепроизводственные затраты», а счёта 26 «Общехозяйственные затраты», а не расходы.

«Расходы по обычным видам деятельности формируют:

- расходы, связанные с приобретением сырья, материалов, товаров и иных материально-производственных запасов;

- расходы, возникающие непосредственно в процессе переработки (доработки) материально-производственных запасов для целей производства продукции, выполнения работ и оказания услуг и их продажи, а также продажи (перепродажи) товаров (расходы по содержанию и эксплуатации основных средств, иных вне оборотных активов, а также по поддержанию их в исправном состоянии, коммерческие расходы, управленческие расходы и др.)».

Если следовать определению, что «расходы - это затраты, больше не создающие будущих экономических выгод, не соответствующие или переставшие соответствовать требованиям признания в качестве актива в балансе», то употребление слова «расходы» в начале каждого пункта перечисления ситуаций является неправомерным. На рис. 1 расходы представлены в более широком смысле слова. А в узком смысле есть выражение «прямые и косвенные расходы», «общепроизводственные и общехозяйственные расходы», «расходы на научно-исследовательские работы» и т.д.

Затраты - это денежные средства или стоимостное выражение средств (активов) организации, переданных другим юридическим или физическим лицам в счет погашения текущих и будущих обязательств (задолженности) в результате приобретения ресурсов, средств труда и прочих обязательных платежей. При этом такие обязательства могут возникать в связи с приобретением сырья, материалов, оплатой труда работников, социальными отчислениями и т.д. (Sirotkin, 2011) Затраты организации включают её расходы на производство, обращение, сбыт продукции, а также на нужды управления, не связанные непосредственно с процессом производства продукта, а также обусловленные проведением за определенный период времени производственных, хозяйственных и финансовых операций и др., в частности, возникающих как последствия чрезвычайных обстоятельств деятельности организации (пожары и др.).

В составе затрат можно выделить следующие:

- затраты, связанные непосредственно с производством продукта, включающие материальные затраты (на основное производство), оплату труда производственных рабочих с отчислениями на социальные нужды;

- затраты на обеспечение и обслуживание основного производства общепроизводственные (на содержание, эксплуатацию оборудования, на освещение, отопление и содержание производственных помещений, оплата труда персонала, связанного с содержанием и обслуживанием производства; амортизационные отчисления, связанные с переносом стоимости основных средств на производимую продукцию, плата за арендуемые машины и помещения производственного назначения и др.;

- общехозяйственные, включающие административно-управленческие расходы; 
- расходы на содержание общехозяйственного персонала, не связанного непосредственно с производственным процессом; амортизационные отчисления на воспроизводство основных средств управленческого и общехозяйственного назначения и расходы на их ремонт; расходы по оплате информационных, аудиторских, консультационных и т.п. услуг; арендная плата за помещения общехозяйственного назначения и др.;

- операционные расходы - затраты и платежи на проведение производственных, хозяйственных и финансовых операций за определенный период времени, включающие непрямые затраты на производство, реализацию продукции, административные и финансовые расходы;

- внереализационные расходы - штрафы, пени за нарушение договоренностей с партнерами; убытки прошлых лет, признанные в отчетном периоде, суммы уценки активов, суммы дебиторской и других задолженностей, нереальных для взыскания, в частности, из-за истечения срока исковой давности, отрицательные курсовые разницы и др.;

- чрезвычайные, возникающие как последствия чрезвычайных обстоятельств хозяйственной деятельности (аварии, стихийные бедствия и др.). (Borisov, 2008).

Затраты можно классифицировать и по другим признакам, что позволяет более обосновано учитывать их величину, принимая во внимание

- зависимость от объемов производства - условно-переменные (зависимые от объемов производства) и условно-постоянные, остающиеся практически неизменными при относительно небольших колебаниях объема выпуска продукции;

- места формирования затрат - статьи калькуляции;

- направления затрат - экономические элементы;

- способ отнесения на себестоимость продукции - прямые, относимые непосредственно на конкретный продукт, и косвенные, относимые через условный измеритель;

- признак однородности затрат - одноэлементные (заработная плата производственных рабочих, амортизационные отчисления и др.) и многоэлементные, включающие более одного вида затрат, например, расходы на содержание и эксплуатацию оборудования включают амортизацию оборудования, используемого в основном производстве; материалы на обслуживание и технический ремонт основного оборудования; заработную плату с отчислениями в социальные фонды рабочих, обслуживающих основное производство; заработную плату работников ОТК с отчислениями в социальные фонды и др. (Efimov and Mel'nik, 2009).

Элементы затрат содержать пять обязательных групп, представленных на рис. 1.1 Статьи затрат определяются предприятием самостоятельно с учетом отраслевой специфики и могут включать следующее:

1. Сырье и материалы.

2. Возвратные отходы (вычитаются).

3. Топливо и энергия на технологические нужды.

4. основная и заработная плата производственных рабочих.

5. Дополнительная заработная плата производственных рабочих.

6. Отчисления на социальное страхование.

7. Расходы на подготовку и освоение производства (так называемые пусковые расходы).

8. Расходы на содержание и эксплуатацию оборудования (затрат на ремонт и амортизация производственного оборудования и т.п.).

9. Цеховые расходы (заработная плата аппарата управления цехов, содержание цеховых зданий).

10. Цеховая себестоимость - сумма затрат на 1-9 статьям калькуляции.

11. Общезаводские расходы (заработная плата аппарата управления завода, содержание административного здания и т.п.).

12. Прочие производственные расходы.

Производственная себестоимость - сумма затрат по 1-11 статьям калькуляции. Коммерческие расходы (затраты на тару, упаковку на складе готовой продукции, перевозку до пункта отправления и др.). 
Полная себестоимость - это сумма затрат по всем вышеперечисленным статьям калькуляции.

На предприятии можно выделить три функциональные сферы его деятельности: производство, администрацию (административно-управленческий аппарат) и сферу реализации и сбыта. В этой связи в каждой сфере можно выделить прямые и косвенные затраты (табл. 1).

Таблица 1

\section{Прямые и косвенные затраты предприятия}

\begin{tabular}{|c|c|c|}
\hline \multirow{2}{*}{$\begin{array}{c}\text { Сфера } \\
\text { деятельности }\end{array}$} & \multicolumn{2}{|c|}{ Затраты } \\
\hline & Прямые & Косвенные \\
\hline $\begin{array}{c}1 . \\
\text { Производство }\end{array}$ & $\begin{array}{c}\text { Заработная плата основных рабочих } \\
\text { Материальные затраты } \\
\text { Отчисления на социальное } \\
\text { страхование }\end{array}$ & $\begin{array}{c}\text { Оплата труда вне сферы } \\
\text { производства, вспомогательные } \\
\text { материалы, электроэнергия, } \\
\text { ремонт, } \\
\text { амортизация, страхование, } \\
\text { аренда, прочие }\end{array}$ \\
\hline $\begin{array}{c}2 . \\
\text { Администрат } \\
\text { ивно- } \\
\text { управленчес } \\
\text { кий аппарат }\end{array}$ & $\begin{array}{c}\text { Заработная плата работников аппарата } \\
\text { Отчисления на социальное } \\
\text { страхование }\end{array}$ & $\begin{array}{c}\text { Электроэнергия, ремонт, } \\
\text { амортизация, аренда, } \\
\text { страхование, телефон, прочие }\end{array}$ \\
\hline $\begin{array}{c}3 . \\
\text { Реализация } \\
\text { и сбыт }\end{array}$ & $\begin{array}{c}\text { Заработная плата работников аппарата } \\
\text { Материальные затраты } \\
\text { Отчисления на социальное } \\
\text { страхование } \\
\text { Плата транспортным организациям }\end{array}$ & \\
\hline
\end{tabular}

Такой подход используется тогда, когда затраты определяются отдельно в каждой сфере. Если рассматривать предприятие, как единое целое, то прямые затраты - это прямые затраты сферы производства, косвенные - все остальные затраты трех сфер.

При этом косвенные затраты включают в себя:

- общепроизводственные расходы - косвенные затраты сферы производства;

- общехозяйственные расходы - прямые и косвенные затраты административноуправленческого аппарата и сферы реализации и сбыта.

Прогнозирование и планирование затрат, связанных с деятельностью организации, это вариантные оптимизационные задачи, предусматривающие минимизацию или приемлемость их уровня либо при максимизации дохода, либо при обеспечении необходимого/достаточного уровня доходности, либо максимально возможного разрыва между полученным доходом и затратами, обусловившими его получение. Последнее положение связано с доходами и затратами, получаемыми от реализации продукции, работ и услуг организации. В этом случае определение величины затрат связано с использованием специальных оптимизационных методов. (Kovalev, 2008).

Учет затрат в различных срезах - задачи прямого счета, поэтому при их решении использоваться также методы прямого счета.

Арсенал инструментальных средств, которые могут использоваться при прогнозировании, планировании, а также при учете и анализе доходов и затрат, достаточно обширный, поэтому при выборе наиболее предпочтительных методов требуется более подробная характеристика, как самих методов, так и специфики складывающихся ситуаций и требований к получаемым результатам.

Использование специальных методов позволяет также грамотно подойти и к формированию себестоимости продукции (выполняемых работ, оказываемых услуг) и 
эффективно управлять ее уровнем с целью получения желаемых результатов деятельности организации.

При оптимизации совокупных доходов и совокупных затрат необходимо учитывать специфику формирования каждого из видов дохода и затрат, то есть общая задача оптимизации может рассматриваться как локальная оптимизация каждой из составляющих.

При решении задач формирования совокупных доходов и затрат или составляющих их элементов необходимо учитывать возможность появления рисков, поскольку ситуация, в которой решаются эти задачи в любом случае будет характеризоваться той или иной степенью неопределенности. Необходимость учитывать возможные риски диктует специфический подход к выбору используемых инструментальных средств, процедурам расчета, к закладываемым в технологии управления доходами/затратами возможных или необходимых корректирующих воздействий.

Современная динамичная среда как внутренняя, так и внешняя требует поиска специальных приемов, методов, технологий, информационного, методического, кадрового и организационного обеспечения выполнения работ, связанных с расчетами как самих величин доходов и затрат и их элементов, так и определения затрат, связанных с противодействием возникающим рискам.

Затраты - один из вечных резервов. Их сокращение во многих случаях не требует серьезных финансовых вложений. Поэтому получить рост прибыли за счет снижения затрат, как правило, легче, чем увеличение объема продаж.

Для снижения расходов необходимо осуществлять: оценку, анализ, планирование и контроль за исполнением плановых заданий по местам возникновения и видам расходов (затрат); поиск резервов обоснованного (в т.ч. с использованием научных методов) снижения себестоимости продукции. Обособление центров ответственности (responsibility centers) по расходам, т.е. подразделений компании, руководство которых имеет определенные ресурсы и полномочия в управлении расходами.

В рамках данной статьи на основе статистических данных по реальному сектору экономики проведем исследование влияния структуры себестоимости продукции на показатель рентабельности продукции.

Согласно методологии Федеральной службы государственной статистики, рентабельность проданных товаров, продукции (работ, услуг) рассчитывается как соотношение между величиной сальдированного финансового результата (прибыль минус убыток) от продажи товаров, продукции (работ, услуг) и себестоимостью проданных товаров, продукции (работ, услуг). В том случае, если получен убыток от продажи товаров, продукции (работ, услуг), имеет место убыточность. Исходные данные для проведения анализа влияния структуры себестоимости на показатель рентабельности продукции представлены в табл. 2.

\section{Исходные данные для проведения анализа влияния структуры себестоимости на показатель рентабельности продукции по видам экономической деятельности в РФ в 2012 г.}

\begin{tabular}{|l|l|l|l|l|l|l|}
\hline $\begin{array}{l}\text { Виды экономической } \\
\text { деятельности }\end{array}$ & $\begin{array}{l}\text { Доля } \\
\text { материальных } \\
\text { затрат, \% }\end{array}$ & $\begin{array}{l}\text { Доля затрат } \\
\text { на оплату } \\
\text { труда, \% }\end{array}$ & $\begin{array}{l}\text { Страховые } \\
\text { взносы, \% }\end{array}$ & $\begin{array}{l}\text { Амортиз } \\
\text { ация, \% }\end{array}$ & $\begin{array}{l}\text { Прочие } \\
\text { затраты }\end{array}$ & $\begin{array}{l}\text { Рентабель- } \\
\text { ность } \\
\text { продукции, } \\
\%\end{array}$ \\
\hline $\begin{array}{l}\text { Сельское хозяйство, } \\
\text { охота и лесное } \\
\text { хозяйство }\end{array}$ & 61,4 & 16,9 & 3,6 & 9 & 9,1 & 10,7 \\
\hline $\begin{array}{l}\text { Рыболовство, } \\
\text { рыбоводство }\end{array}$ & 53,9 & 19,6 & 4,2 & 4,3 & 18 & 16,2 \\
\hline $\begin{array}{l}\text { Добыча полезных } \\
\text { ископаемых }\end{array}$ & 33,9 & 8,9 & 2,1 & 10,3 & 44,8 & 28 \\
\hline
\end{tabular}




\begin{tabular}{|c|c|c|c|c|c|c|}
\hline $\begin{array}{l}\text { Обрабатывающие } \\
\text { производства }\end{array}$ & 73,4 & 9,6 & 2,6 & 3,2 & 11,2 & 10,7 \\
\hline $\begin{array}{l}\text { Производство и } \\
\text { распределение } \\
\text { электроэнергии, газа } \\
\text { и воды }\end{array}$ & 62,7 & 13,4 & 3,5 & 7,9 & 12,5 & 3,9 \\
\hline Строительство & 55,2 & 18,8 & 4,8 & 2,8 & 18,4 & 5 \\
\hline $\begin{array}{l}\text { Оптовая и розничная } \\
\text { торговля; ремонт } \\
\text { автотранспортных } \\
\text { средств, мотоциклов, } \\
\text { бытовых изделий и } \\
\text { предметов личного } \\
\text { пользования }\end{array}$ & 45,1 & 13,3 & 3,2 & 9,8 & 28,6 & 6,7 \\
\hline $\begin{array}{l}\text { Гостиницы и } \\
\text { рестораны }\end{array}$ & 36,7 & 24,6 & 6,8 & 3,6 & 28,3 & 5,9 \\
\hline Транспорт и связь & 39,5 & 17,7 & 4,5 & 8,7 & 29,6 & 11,1 \\
\hline из них связь & 15,6 & 18 & 4,5 & 14,4 & 47,5 & 23,7 \\
\hline $\begin{array}{l}\text { Операции с } \\
\text { недвижимым } \\
\text { имуществом, аренда } \\
\text { и предоставление } \\
\text { услуг }\end{array}$ & 32 & 29,3 & 6,7 & 4,6 & 27,4 & 10,6 \\
\hline $\begin{array}{l}\text { Государственное } \\
\text { управление и } \\
\text { обеспечение военной } \\
\text { безопасности; } \\
\text { социальное } \\
\text { страхование }\end{array}$ & 19,5 & 46,3 & 12,3 & 2,5 & 19,4 & 8,3 \\
\hline Образование & 13,3 & 46,8 & 11,5 & 2,1 & 26,3 & 2,5 \\
\hline $\begin{array}{l}\text { Здравоохранение и } \\
\text { предоставление } \\
\text { социальных услуг }\end{array}$ & 28,6 & 38,5 & 10,2 & 4,4 & 18,3 & 6,6 \\
\hline $\begin{array}{l}\text { Предоставление } \\
\text { прочих } \\
\text { коммунальных, } \\
\text { социальных и } \\
\text { персональных услуг }\end{array}$ & 27,5 & 29,2 & 6,5 & 4 & 32,8 & $-5,8$ \\
\hline
\end{tabular}

Источник: составлено по данным Федеральной службы государственной статистики. Режим доступа: http://www.gks.ru/wps/wcm/connect/rosstat_main/rosstat/ru/statistics/finance/\#

На первом этапе проанализируем взаимосвязь между долей материальных затрат и уровнем рентабельности продукции (рис. 2). 


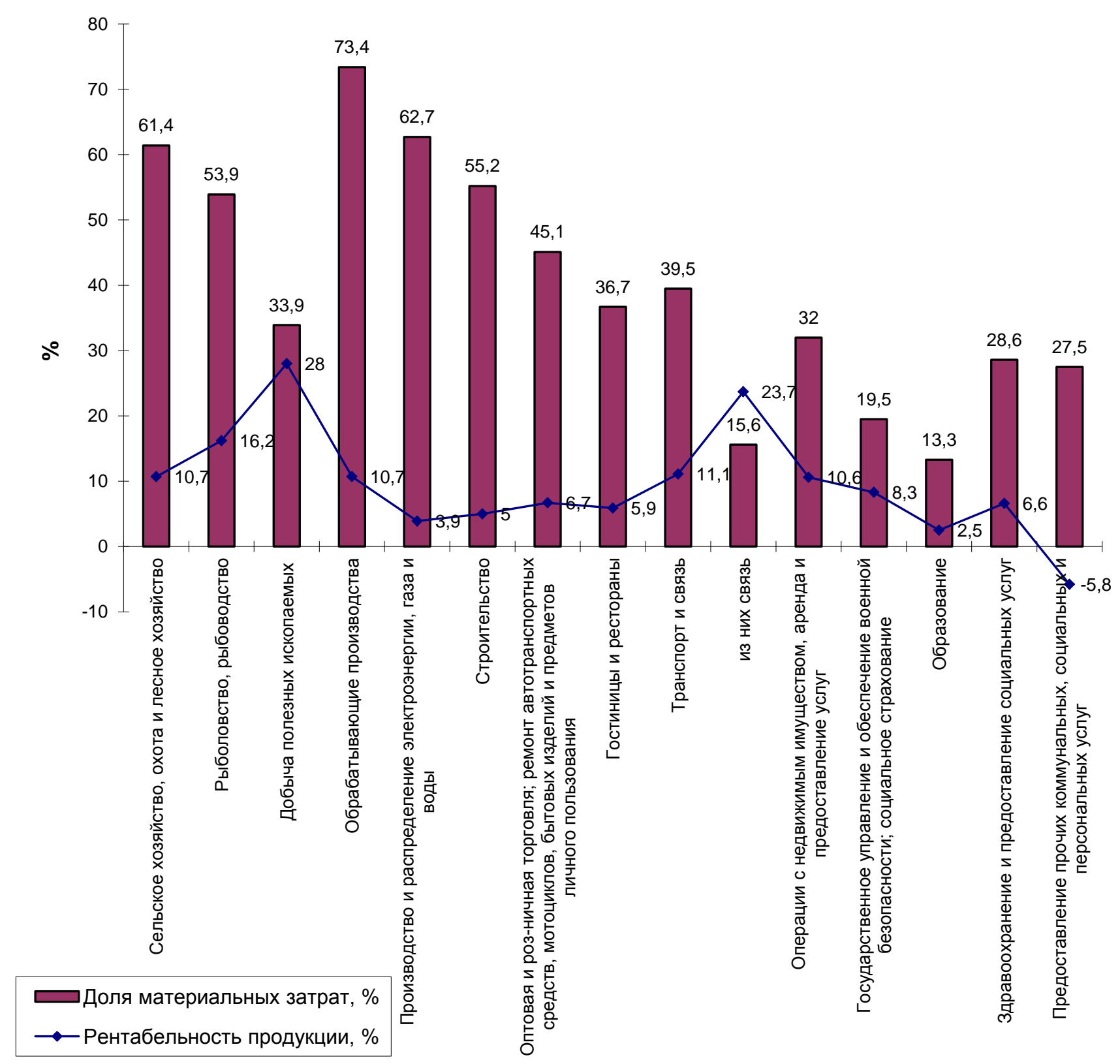

Puc. 2. Взаимосвязь между долей материальных затрат и уровнем рентабельности продукции по видам экономической деятельности в РФ в 2012 г., \%

Проведенный корреляционный анализ показал, что коэффициент корреляции (r) равен -о.036. Связь между исследуемыми признаками - обратная, теснота (сила) связи по шкале Чеддока - слабая.

Число степеней свободы (f) составляет 13.

$\mathrm{t}$-критерий Стьюдента равен -0.129

Критическое значение t-критерия Стьюдента при данном числе степеней свободы составляет 2.16. tнабл < tкрит, зависимость признаков статистически не значима (p>0,05)

Уравнение парной линейной регрессии: $\mathrm{y}=10.38431-0.01633$ * $\mathrm{x}$

Коэффициент детерминации $\mathrm{r}^{2}$ равен 0.001 (факторный признак х определяет $0.1 \%$ дисперсии зависимого признака у). Средняя ошибка аппроксимации (характеризует адекватность регрессионной модели) составляет 74.2 \%. Далее было проведено исследование взаимосвязи между долей затрат на оплату труда и уровнем рентабельности продукции (рис. 3). 


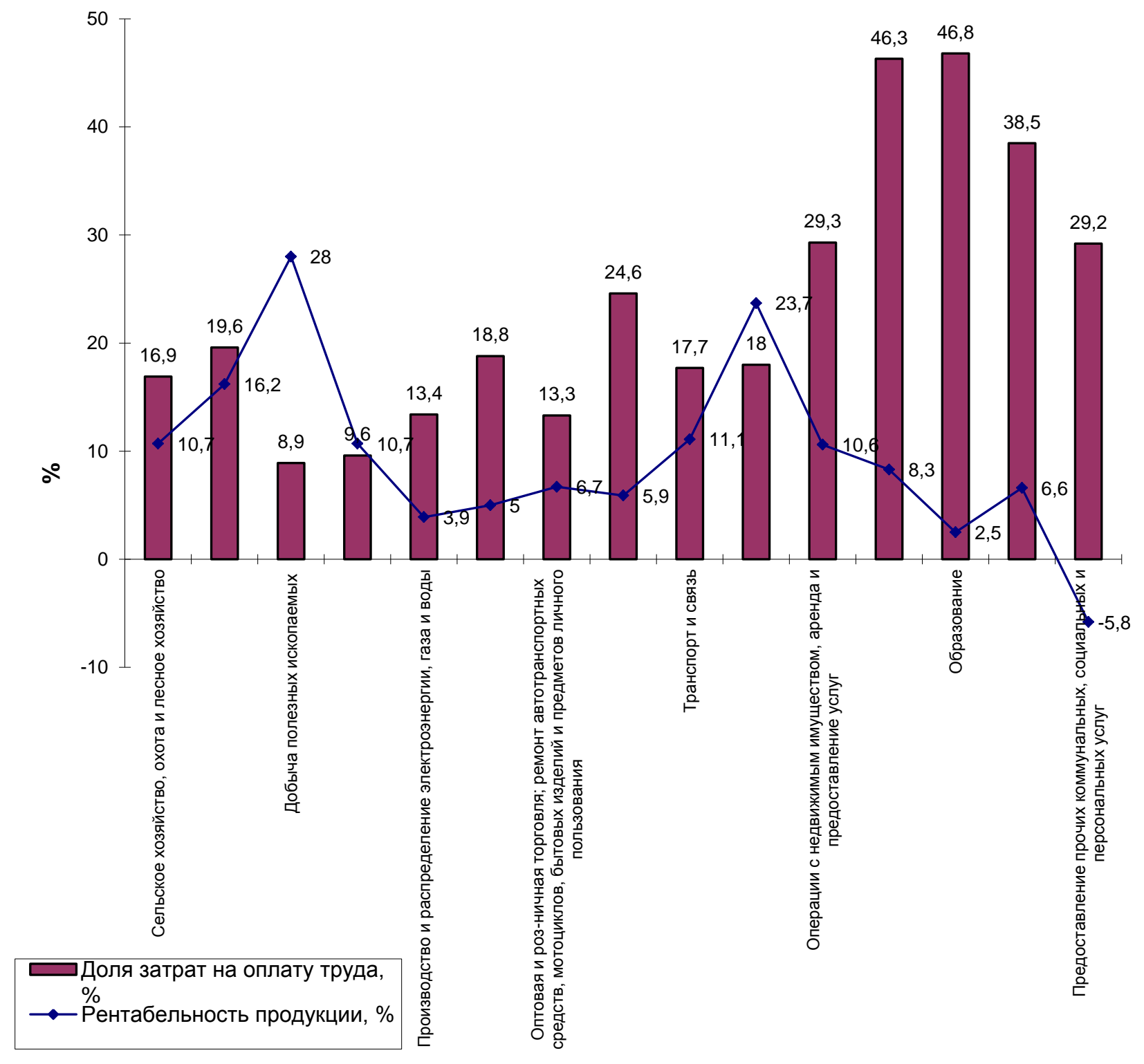

Puc. 3. Взаимосвязь между долей затрат на оплату труда и уровнем рентабельности продукции по видам экономической деятельности в РФ в 2012 г., \%

В результате проведенного корреляционного анализа было получено, что коэффициент корреляции (r) равен -0.429. Связь между исследуемыми признаками обратная, теснота (сила) связи по шкале Чеддока - умеренная. Число степеней свободы (f) составляет 13.

$\mathrm{t}$-критерий Стьюдента равен -1.715

Критическое значение $\mathrm{t}$-критерия Стьюдента при данном числе степеней свободы составляет 2.16. tнабл < tкрит, зависимость признаков статистически не значима (p>0,05)

Уравнение парной линейной регрессии: $\mathrm{y}=16.54212-0.29015 * \mathrm{x}$

Коэффициент детерминации $\mathrm{r}^{2}$ равен 0.184 (факторный признак х определяет $18.4 \%$ дисперсии зависимого признака у). Средняя ошибка аппроксимации (характеризует адекватность регрессионной модели) составляет 66.4 \%. На следующем этапе изучалось влияние доли страховых взносов в себестоимости продукции на уровень рентабельности продукции (рис. 4). 


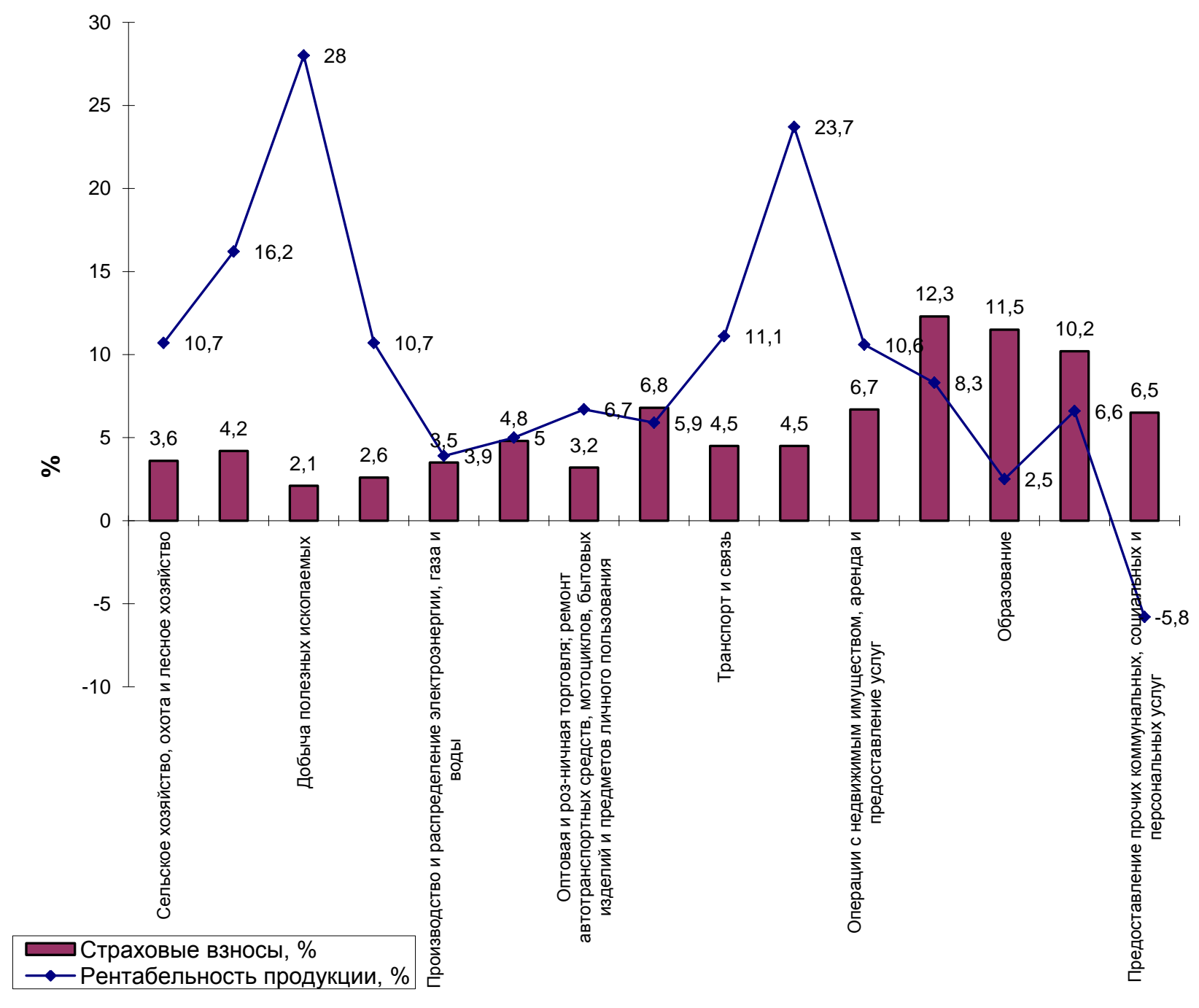

Puc. 4. Взаимосвязь между долей страховых взносов и уровнем рентабельности продукции по видам экономической деятельности в РФ в 2012 г., \%

Расчеты показали, что коэффициент корреляции (r) равен -0.444, связь между исследуемыми признаками - обратная, теснота (сила) связи по шкале Чеддока - умеренная. Число степеней свободы (f) составляет 13. t-критерий Стьюдента равен -1.786

Критическое значение t-критерия Стьюдента при данном числе степеней свободы составляет 2.16. tнабл < tкрит, зависимость признаков статистически не значима $(\mathrm{p}>0,05)$

Уравнение парной линейной регрессии: $\mathrm{y}=16.71905-1.16429 * \mathrm{x}$

Коэффициент детерминации $\mathrm{r}^{2}$ равен 0.197 (факторный признак х определяет $19.7 \%$ дисперсии зависимого признака у). Средняя ошибка аппроксимации (характеризует адекватность регрессионной модели) составляет 65.1\%. Далее проведем исследование влияния доли амортизационных отчислений в составе себестоимости на уровень рентабельности продукции (рис. 5). 


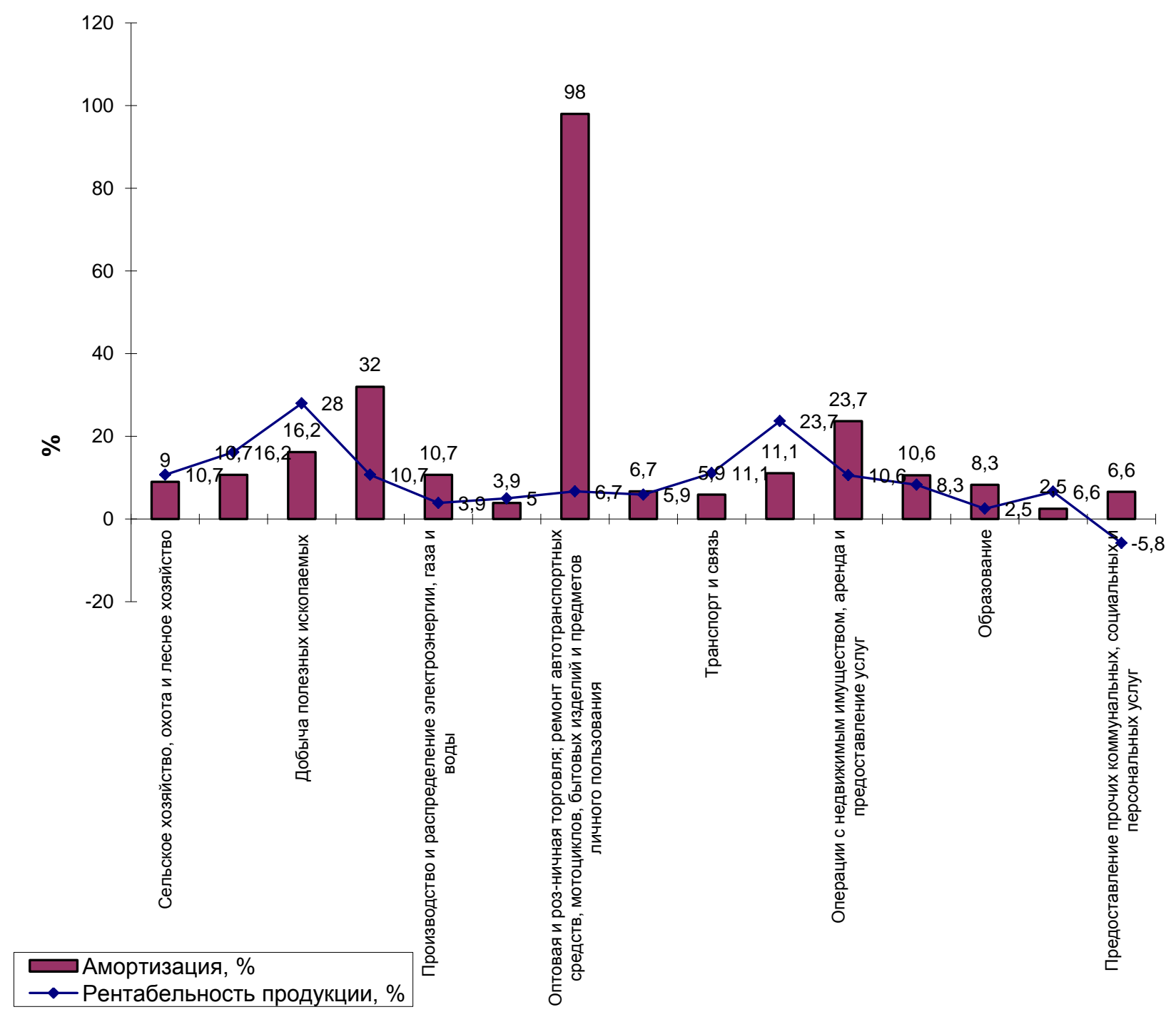

Puc. 5. Взаимосвязь между долей амортизационных отчислений и уровнем рентабельности продукции по видам экономической деятельности в РФ в 2012 г., \%

Было установлено, что коэффициент корреляции (r) между признаками равен 0.594. Связь между исследуемыми признаками - прямая, теснота (сила) связи по шкале Чеддока заметная. Число степеней свободы (f) составляет 13

$\mathrm{t}$-критерий Стьюдента равен 2.659

Критическое значение t-критерия Стьюдента при данном числе степеней свободы составляет 2.16. tнабл > tкрит, зависимость признаков статистически значима $(\mathrm{p}<0,05)$.

Уравнение парной линейной регрессии: $\mathrm{y}=1.26032+1.38147^{*} \mathrm{x}$.

Коэффициент детерминации $\mathrm{r}^{2}$ равен 0.352 (факторный признак $\mathrm{x}$ определяет 35.199999999999996 \% дисперсии зависимого признака у). Средняя ошибка аппроксимации (характеризует адекватность регрессионной модели) составляет $58.0 \%$.

На последнем этапе исследования изучалось влияние взаимосвязи доли прочих затрат на уровень рентабельности продукции (рис. 6). 


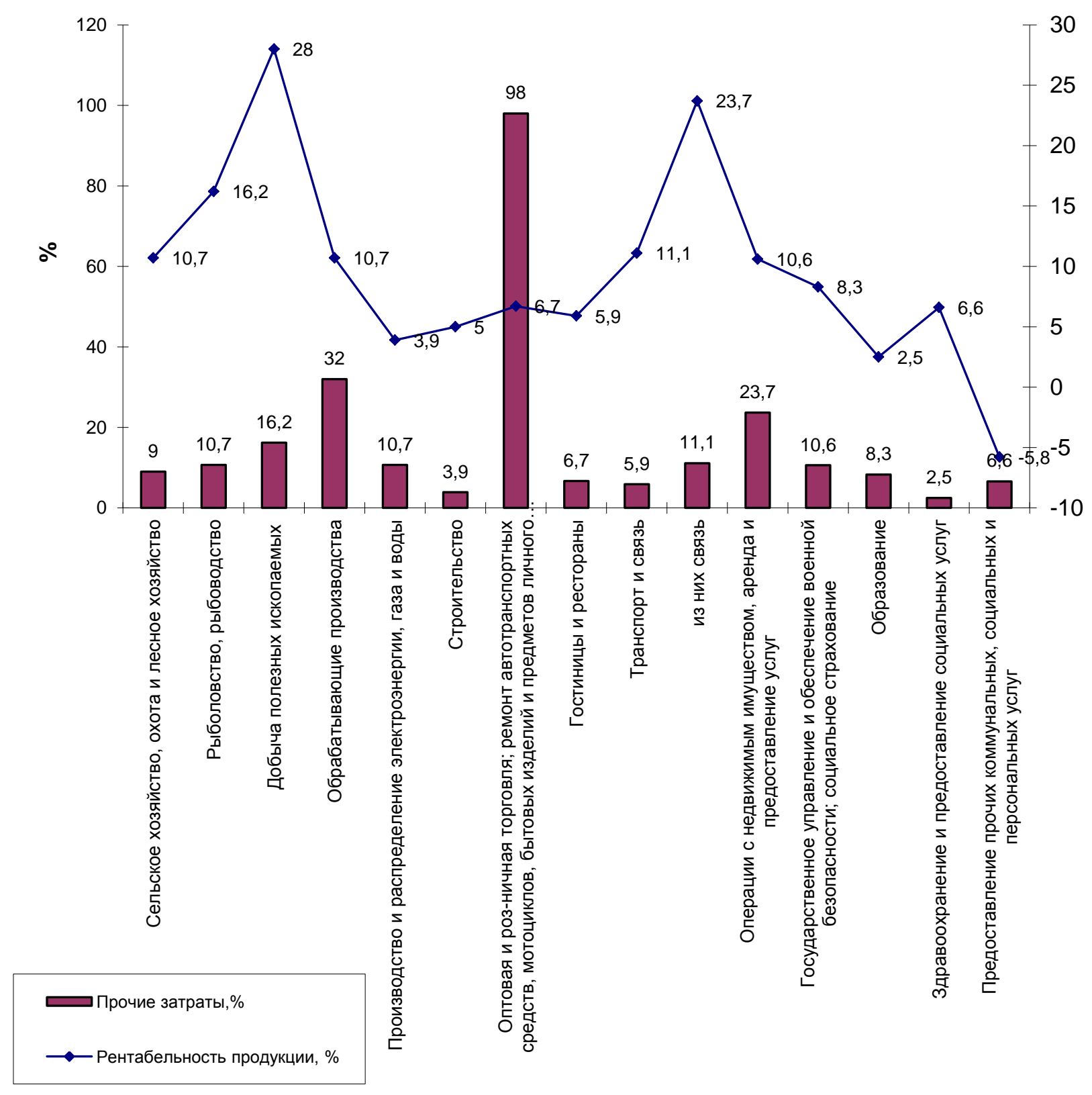

Puc. 6. Взаимосвязь между долей прочих затрат и уровнем рентабельности продукции по видам экономической деятельности в РФ в 2012 г., \%

Проведенный анализ показал, что коэффициент корреляции (r) равен 0.451

Связь между исследуемыми признаками - прямая, теснота (сила) связи по шкале Чеддока - умеренная. Число степеней свободы (f) составляет 13. t-критерий Стьюдента равен 1.820. Критическое значение t-критерия Стьюдента при данном числе степеней свободы составляет 2.16. tнабл < tкрит, зависимость признаков статистически не значима ( $\mathrm{p}>0,05)$.

Уравнение парной линейной регрессии: $\mathrm{y}=1.62108+0.32799$ * $\mathrm{x}$

Коэффициент детерминации $\mathrm{r}^{2}$ равен 0.203 (факторный признак х определяет $20.3 \%$ дисперсии зависимого признака у). Средняя ошибка аппроксимации (характеризует адекватность регрессионной модели) составляет $68.7 \%$

Таким образом, можно сделать следующие выводы. Роль затрат в деятельности предприятия очень велика. С одной стороны, с их помощью обеспечивается нормальная 
деятельность предприятия, с другой - затратами нужно управлять. Понятие «затраты» отличается от понятия «расходы» тем, что затраты являются частью себестоимости и включаются в нее в виде элементов или статей затрат.

В результате проведенного исследования было установлено, что между такими признаками, как доля материальные затрат и уровень рентабельности продукции связь обратная, теснота (сила) связи по шкале Чеддока - слабая. Между такими признаками, как доля затрат на оплату труда и страховые взносы и уровнем рентабельности продукции связь обратная, теснота (сила) связи по шкале Чеддока - умеренная. Между такими признаками, как доля амортизационных отчислений и уровнем рентабельности продукции связь прямая, теснота (сила) связи по шкале Чеддока - заметная. Между такими признаками, как доля прочих затрат и уровнем рентабельности продукции связь прямая, теснота (сила) связи по шкале Чеддока - умеренная. Таким образом, лишь амортизационные отчисления оказывают положительное влияние на уровень рентабельности продукции. Все остальные виды затрат снижают уровень рентабельности продукции. Наиболее сильное снижение уровня рентабельности продукции наблюдается под влиянием затрат на оплату труда и страховых взносов, а также прочих затрат.

Теоретическая значимость исследования состоит в том, что полученные в его результате теоретические выводы и практические рекомендации позволяют рекомендовать применение экономико математического моделирования в качестве эффективного инструмента анализа влияния себестоимости продукта на эффективность деятельности предпринимательских структур, который может быть внедрен в деятельности субъектов хозяйствования и всей экономической системы Российской Федерации в целом.

\section{Примечания:}

1. Борисов Е.Ф. Основы экономики. Учебник для ССУЗов. М.: Дрофа. 2008. 320 с.

2. Бурмистрова Л.М. Финансы организаций (предприятий). Учеб. пособие. М.: ИНФРА-М, 2009. 240 c.

3. Ефимова О.В., Мельник М.В. Анализ финансовой отчетности. М.: Омега-Л, 2009. 451 с.

4. Ковалев В.В. Курс финансового менеджмента. М., 2008. С. 186.

5. Ковалев В.В., Ковалев Вит. В. Финансовый менеджмент. Конспект лекций с задачами и тестами. М.: Проспект, 2011. С. 127.

6. Когденко В.Г. Краткосрочная и долгосрочная финансовая политика и др. М., 2011. $471 \mathrm{c}$.

7. Официальный сайт Федеральной службы государственной статистики. Режим доступа: http://www.gks.ru/wps/wcm/connect/rosstat_main/rosstat/ru/statistics/finance/\#

8. Приказ Минфина России от 06.05.1999 № 33н (ред. от 27.04.2012) «Об утверждении Положения по бухгалтерскому учету «Расходы организации» ПБУ 10/99» (Зарегистрировано в Минюсте России 31.05.1999 № 1790)

9. Сироткин С.А. Финансовый менеджмент на предприятии. Финансовый менеджмент на предприятии: учебник / С. А. Сироткин, Н. Р. Кельчевская. 2-е изд., перераб. и доп. М.: ЮНИТИ-ДАНА, 2011. С.38.

10. Управление финансами. Финансы предприятий: Учебник / Под ред. А.А. Володина. М.: ИНФРА-М, 2011. С. 277.

11. Чернобривая Н.А., Гладкова Н.В. Методологические основы применения понятий затрат, расходов, издержек в теории и на практике // Балтийский экономический журнал. 2010. № 2. C. 195-206.

12.Lyasnikov N.V., Dudin M.N., Sekerin V.D., Veselovsky M.Y., Aleksakhina V.G. The national innovation system: the conditions of its making and factors in its development // Life Science Journal. 2014. Vol. 11, № 8. P. 549-552.

13.Dudin M.N., Lyasnikov N.V., Yahyaev M.A., KuznetzovA.V. The organization approaches peculiarities of an industrial enterprises financial management // Life Science Journal. 2014. Vol. 11, No.9, P. 333-336.

14.Baranenko S.P., Dudin M.N., Ljasnikov N.V., Busygin K.D. Using environmental approach to innovation-oriented development of industrial enterprises // American Journal of Applied Sciences. 2013. Vol. 11, No.2, P. 189-194. 


\title{
References:
}

1. Borisov E.F. Fundamentals of the economy. A textbook for Colleges. M.: The Houbara Bustard. 2008.

2. Burmistrova L.M. Finance organizations (enterprises). The textbook. the allowance. M.: INFRA-M, 2009.

3. Efimov O., Mel'nik M.V. Analysis of financial statements): Omega-L, 2009.

4.Kovalev V.V. Course in financial management. M., 2008.

5. Kovalev V.V., Kovalev Wit.W. Financial management. Lecture notes with tasks and tests. M.: Prospect, 2011.

6. Kogdenko V.G. Short-term and long-term financial policies and other. M, 2011.

7. Official site of the Federal service of state statistics. Mode of access: http://www.gks.ru/wps/wcm/connect/rosstat_main/rosstat/ru/statistics/finance/\#

8. The Russian Finance Ministry order dated 06.05.1999 № n (as amended on 27.04.2012) "On approval of Provisions on accounting "expenses of the organization" PBU 10/99" (Registered in Ministry of justice of Russia 31.05.1999 № 1790).

9. Sirotkin S.A. Financial management in the enterprise. - Financial management in the enterprise: textbook / S. A. Sirotkin, N. R. Kielczewska. - 2nd ed., revised and enlarged extra. M. : UNITY-DANA, 2011. №.38.

10. Managing finances. Business Finance: Textbook /Ed. by A. Volodin. M.: INFRA-M, 2011.

11. Chernobriva N.A., Gladkova N.V. Methodological basis for the application of the concepts of costs, expenses, costs in theory and practice // the Baltic economic journal. 2010. № 2.

12. Lyasnikov N.V., Dudin M.N., Sekerin V.D., Veselovsky M.Y., Aleksakhina V.G. The national innovation system: the conditions of its making and factors in its development // Life Science Journal. 2014. Vol. 11, № 8. P. 549-552.

14.Dudin M.N., Lyasnikov N.V., Yahyaev M.A., KuznetzovA.V. The organization approaches peculiarities of an industrial enterprises financial management // Life Science Journal. 2014. Vol. 11, No.9, P. 333-336.

15.Baranenko S.P., Dudin M.N., Ljasnikov N.V., Busygin K.D. Using environmental approach to innovation-oriented development of industrial enterprises // American Journal of Applied Sciences. 2013. Vol. 11, No.2, P. 189-194.

УДК 330

\section{Экономико-математическое моделирование влияния себестоимости продукта на эффективность деятельности предпринимательских структур}

\author{
${ }^{1}$ Михаил Николаевич Дудин \\ 2 Николай Васильевич Лясников \\ 3 Александр Сергеевич Сенин
}

1 Российская академия народного хозяйства и государственной службы при Президенте
Российской Федерации (РАНХ и ГС), Российская Федерация
119571, Москва, проспект Вернадского, 82, строение 1
Доктор экономических наук, доцент
E-mail: dudinmn@mail.ru
2 Доктор экономических наук, профессор
3 Доктор экономических наук, профессор

Аннотация. Предмет / тема. Один из ключевых элементов управления операционной деятельностью организации - управление расходами, поскольку расходы, представляя собой платежи, которые необходимо осуществить, чтобы привлечь и удержать экономические ресурсы, являются одним из основных факторов, определяющих размер финансовых результатов организации, рентабельность инвестированного капитала, и, в конечном счете, стоимость бизнеса. 
Цель / задачи. Целью данной работы является исследование влияния структуры себестоимости продукции на показатель рентабельности продукции.

Методология. Для выполнения данной статьи были использованы такие методы анализа, как правовой, сравнительный, экономико-статистический и корреляционный.

Выводы / значимость. Практическое значение данной работы заключается в том, что в статье уточнено понятие и состав себестоимости продукции, выведены уравнения парной линейной регрессии между долей затрат в составе себестоимости и уровнем рентабельности продукции по видам экономической деятельности в РФ в 2012 г. Полученные модели позволяют, зная долю затрат в структуре себестоимости по различным видам экономической деятельности в РФ в 2012 г. оценить средний уровень рентабельности продукции.

Ключевые слова: себестоимость; затраты; расходы; состав себестоимости; структура себестоимости; рентабельность продукции. 